\title{
Barriers to Early Hospital Discharge: A Cross-Sectional Study at Five Academic Hospitals
}

\author{
Jeff Zoucha, MD 1,2, Madelyne Hull, MPH ${ }^{3}$, Angela Keniston, MSPH ${ }^{2,3}$, Katarzyna Mastalerz, MD²,4 Roswell Quinn, MD, PhD5, \\ Arnold Tsai, MD ${ }^{6}$, Jacob Berman, MD7 , Jennifer Lyden, MD 1,2, Sarah A. Stella, MD 1,2, Marisa Echaniz, MD ${ }^{1,2}$, Nicholas Scaletta, \\ MD ${ }^{1,2}$, Karina Handoyo, MD ${ }^{2,4}$, Estebes Hernandez, MD', Inderpreet Saini, MD ${ }^{5}$, Aneesah Smith, MD ${ }^{6}$, Andrew Young, DO ${ }^{6}$, \\ Meghaan Walsh, MD, Mark Zaros, MD7, Richard K. Albert, MD, Marisha Burden, MD²,
}

${ }^{1}$ Division of Hospital Medicine, Denver Health, Denver Colorado; ${ }^{2}$ Division of Hospital Medicine, University of Colorado, Denver, Colorado; ${ }^{3}$ Department of Medicine, Denver Health, Denver, Colorado; ${ }^{4}$ Presbyterian St-Luke's Medical Center, Denver, Colorado; ${ }^{5}$ University of California Los Angeles-Ronald Reagan, Los Angeles, California; 'Division of Geriatric, Hospital, Palliative and General Internal Medicine, Keck School of Medicine of University of Southern California, Los Angeles, California; ${ }^{7}$ University of Washington, Harborview Medical Center, Seattle, Washington; ${ }^{8}$ Department of Medicine, University of Colorado, Denver, Colorado.

BACKGROUND: Understanding the issues delaying hospital discharges may inform efforts to improve hospital throughput.

OBJECTIVE: This study was conducted to identify and determine the frequency of barriers contributing to delays in placing discharge orders.

DESIGN: This was a prospective, cross-sectional study. Physicians were surveyed at approximately 8:00 AM, 12:00 $P M$, and 3:00 PM and were asked to identify patients that were "definite" or "possible" discharges and to describe the specific barriers to writing discharge orders.

SETTING: This study was conducted at five hospitals in the United States.

PARTICIPANTS: The study participants were attending and housestaff physicians on general medicine services.

PRIMARY OUTCOMES AND MEASURES: Specific barriers to writing discharge orders were the primary outcomes; the secondary outcomes included discharge order time for high versus low team census, teaching versus nonteaching services, and rounding style.
RESULTS: Among 1,584 patient evaluations, the most common delays for patients identified as "definite" discharges $(n=949)$ were related to caring for other patients on the team or waiting to staff patients with attendings. The most common barriers for patients identified as "possible" discharges $(n=1,237)$ were awaiting patient improvement and for ancillary services to complete care. Discharge orders were written a median of 43-58 minutes earlier for patients on teams with a smaller versus larger census, on nonteaching versus teaching services, and when rounding on patients likely to be discharged first (all $P<.003$ ).

CONCLUSIONS: Discharge orders for patients ready for discharge are most commonly delayed because physicians are caring for other patients. Discharges of patients awaiting care completion are most commonly delayed because of imbalances between availability and demand for ancillary services. Team census, rounding style, and teaching teams affect discharge times. Journal of Hospital Medicine 2018;13:816-822. () 2018 Society of Hospital Medicine ospital discharges frequently occur in the afternoon or evening hours. ${ }^{1-5}$ Late discharges can adversely affect patient flow throughout the hospital, $3,6-9$ which, in turn, can result in delays in care, ${ }^{10-16}$ more medication errors, ${ }^{17}$ increased mortality, ${ }^{18-20}$ longer lengths of stay, ${ }^{20-22}$ higher costs, ${ }^{23}$ and lower patient satisfaction. ${ }^{24}$

Various interventions have been employed in the attempts to find ways of moving discharge times to earlier in the day,

*Address for correspondence: Marisha Burden, MD, Division of Hospital Medicine, University of Colorado School of Medicine, 12401 East 17th Avenue, Mailstop F-782, Aurora, Colorado, 80045; Telephone: 720-848-4289; Fax: 720848-4293; E-mail: marisha.burden@ucdenver.edu

Additional Supporting Information may be found in the online version of this article.

Received: April 19, 2018; Revised: June 29, 2018; Accepted: July 5, 2018

() 2018 Society of Hospital Medicine DOI 10.12788/jhm.3074 including preparing the discharge paperwork and medications the previous night, ${ }^{25}$ using checklists, ${ }^{1,25}$ team huddles, ${ }^{2}$ providing real-time feedback to unit staff, ${ }^{1}$ and employing multidisciplinary teamwork. ${ }^{1,26,25,26}$

The purpose of this study was to identify and determine the relative frequency of barriers to writing discharge orders in the hopes of identifying issues that might be addressed by targeted interventions. We also assessed the effects of daily team census, patients being on teaching versus nonteaching services, and how daily rounds were structured at the time that the discharge orders were written.

\section{METHODS}

Study Design, Setting, and Participants

We conducted a prospective, cross-sectional survey of housestaff and attending physicians on general medicine teaching and nonteaching services from November 13, 2014, through 
TABLE 1. Hospital, Provider, and Service Characteristics

\begin{tabular}{|c|c|c|c|c|c|c|}
\hline & DH & PSL & UCLA & LAC/USC & HMC & All sites \\
\hline Hospital beds, N & 525 & 477 & 520 & 600 & 413 & 2,535 \\
\hline Definite & 384 (42) & 137 (15) & $130(14)$ & $114(12)$ & $153(17)$ & $918(100)$ \\
\hline Possible & $73(37)$ & $16(8)$ & $13(7)$ & $80(40)$ & $17(9)$ & $199(100)$ \\
\hline No discharge & $190(41)$ & $44(9)$ & $84(18)$ & $41(9)$ & $108(23)$ & $467(100)$ \\
\hline \multicolumn{7}{|l|}{ Provider type surveyed, $\mathrm{N}(\%)$} \\
\hline Attending & $31(33)$ & $8(18)$ & $5(11)$ & 0 & $11(30)$ & $55(22)$ \\
\hline Residents & $62(67)$ & $37(82)$ & $41(89)$ & $33(100)$ & $26(70)$ & $199(78)$ \\
\hline \multicolumn{7}{|l|}{ Service type, N (\%) } \\
\hline \multicolumn{7}{|l|}{ Rounding style, N (\%) } \\
\hline Sickest patients first & $59(40)$ & $12(17)$ & $23(27)$ & $55(77)$ & $11(11)$ & $160(33)$ \\
\hline Room-by-room & $22(15)$ & $13(18)$ & $14(17)$ & $10(14)$ & $69(66)$ & $128(27)$ \\
\hline Newest patients first & $10(7)$ & $35(49)$ & $25(30)$ & $1(1)$ & $7(7)$ & $78(16)$ \\
\hline Patients ready for discharge first & $11(8)$ & $11(15)$ & $6(7)$ & $1(1)$ & $6(6)$ & $35(7)$ \\
\hline All other rounding styles & $1(1)$ & $1(1)$ & $16(19)$ & $5(7)$ & $11(11)$ & $34(7)$ \\
\hline Missing & $43(29)$ & 0 & 0 & 0 & 0 & $43(9)$ \\
\hline Starting daily census, median (IQR)a & $11(9,12)$ & $10(8,11.5)$ & $10(7,13)$ & $14(13,15.0)$ & $9(7,11)$ & $11(8,13)$ \\
\hline Discharge order time, median (IQR) & $12: 02(11: 00,13: 50)$ & $11: 06(10: 20,12: 04)$ & $12: 49(11: 16,15: 00)$ & $12: 29(11: 26,14: 10)$ & $10: 52(8: 52,12: 21)$ & $11: 50(10: 35,13: 45)$ \\
\hline
\end{tabular}

${ }^{a}$ Data presented at the provider-evaluation level (ie, data collected each day a provider was called).

bervice type is missing from 3 evaluations for 3 patients by 1 provider.

Abbreviations: DH, Denver Health; HMC, Harborview Medical Center; IQR, interquartile range; LAC \& USC, Los Angeles County and University of Southern California; PSL, Presbyterian St. Luke's Medical Center; UCLA, University of California Los Angeles.

May 31, 2016. The study was conducted at the following five hospitals: Denver Health Medical Center (DHMC) and Presbyterian/Saint Luke's Medical Center (PSL) in Denver, Colorado; Ronald Reagan University (UCLA) and Los Angeles County/University of Southern California Medical Center (LAC+USC) in Los Angeles, California; and Harborview Medical Center (HMC) in Seattle, Washington. The study was approved by the Colorado Multi-Institutional Review Board as well as by the review boards of the other participating sites.

\section{Data Collection}

The results of the focus groups composed of attending physicians at DHMC were used to develop our initial data collection template. Additional sites joining the study provided feedback, leading to modifications (Appendix 1).

Physicians were surveyed at three different time points on study days that were selected according to the convenience of the investigators. The sampling occurred only on weekdays and was done based on the investigators' availability. Investigators would attempt to survey as many teams as they were able to but, secondary to feasibility, not all teams could be surveyed on study days. The specific time points varied as a function of physician workflows but were standardized as much as possible to occur in the early morning, around noon, and midafternoon on weekdays. Physicians were contacted either in person or by telephone for verbal consent prior to administering the first survey. All general medicine teams were eligible. For teaching teams, the order of contact was resident, intern, and then attending based on which physician was available at the time of the survey and on which member of the team was thought to know the patients the best. For the nonteaching services, the attending physicians were contacted.

During the initial survey, the investigators assessed the provider role (ie, attending or housestaff), whether the service was a teaching or a nonteaching service, and the starting patient census on that service primarily based on interviewing the provider of record for the team and looking at team census lists. Physicians were asked about their rounding style (ie, sickest patients first, patients likely to be discharged first, room-by-room, most recently admitted patients first, patients on the team the 
TABLE 2. Physician-Perceived Barriers that Delayed Entering Discharge Orders on Patients Identified as Definite Discharges at any Time Point by All Service Types and Separated by Teaching Team or Nonteaching Team ${ }^{\mathrm{a}}$

\begin{tabular}{|c|c|c|c|c|c|c|c|c|c|}
\hline \multirow[b]{2}{*}{ Patients Identified as Definite Discharges } & \multicolumn{3}{|c|}{ All Service Types } & \multicolumn{3}{|c|}{ Teaching } & \multicolumn{3}{|c|}{ Nonteaching } \\
\hline & $\begin{array}{c}\text { AM } \\
(N=314)\end{array}$ & $\begin{array}{c}\text { Noon } \\
(N=608)\end{array}$ & $\begin{array}{c}\mathrm{PM}^{\mathrm{b}} \\
(\mathrm{N}=461)\end{array}$ & $\begin{array}{c}A M \\
N=222\end{array}$ & $\begin{array}{c}\text { Noon } \\
N=428\end{array}$ & $\begin{array}{c}\mathrm{PM}^{\mathrm{b}} \\
\mathrm{N}=349\end{array}$ & $\begin{array}{c}\mathrm{AM} \\
\mathrm{N}=92\end{array}$ & $\begin{array}{c}\text { Noon } \\
N=177\end{array}$ & $\begin{array}{c}\mathrm{PM}^{\mathrm{b}} \\
\mathrm{N}=111\end{array}$ \\
\hline Newly identified as definite discharge, N (\%) & $314(100)$ & $376(62)$ & $270(59)$ & $222(100)$ & $267(62)$ & $205(59)$ & $92(100)$ & $106(60)$ & $65(59)$ \\
\hline $\begin{array}{l}\text { Patients identified as definite discharges } \\
\text { without discharge orders }\end{array}$ & $261(83)$ & $181(30)$ & $55(12)$ & $187(84)$ & $149(35)$ & $49(14)$ & $74(80)$ & $31(18)$ & $6(5)$ \\
\hline \multicolumn{10}{|l|}{ Caring for other patients } \\
\hline Rounding on all patients first & $96(37)$ & $52(29)$ & 0 & $79(42)$ & $51(34)$ & $0(0)$ & $17(23)$ & $1(3)$ & $0(0)$ \\
\hline Managing nonurgent issues with other patients & $45(17)$ & $41(23)$ & $10(18)$ & $17(9)$ & $34(23)$ & $9(18)$ & $28(38)$ & $7(23)$ & $1(17)$ \\
\hline Managing urgent issues on other sick patients & $21(8)$ & $23(13)$ & $5(9)$ & $10(5)$ & $16(11)$ & $5(10)$ & $11(15)$ & $7(23)$ & $0(0)$ \\
\hline Finishing other discharges & $15(6)$ & $32(18)$ & $17(31)$ & $4(2)$ & $21(14)$ & $13(27)$ & $11(15)$ & $11(35)$ & $4(67)$ \\
\hline \multicolumn{10}{|l|}{ Teaching-related issues } \\
\hline Needing to staff with attending & $82(31)$ & $4(2)$ & 0 & $81(43)$ & $4(3)$ & $0(0)$ & $1(1)$ & $0(0)$ & $0(0)$ \\
\hline Other teaching activities & $3(1)$ & $3(2)$ & 0 & $3(2)$ & $2(1)$ & $0(0)$ & $0(0)$ & $1(3)$ & $0(0)$ \\
\hline Finishing the discharge paperwork & $35(13)$ & $41(23)$ & $25(45)$ & $26(14)$ & $38(26)$ & $24(49)$ & $9(12)$ & $2(6)$ & $1(17)$ \\
\hline \multicolumn{10}{|l|}{ Other issues } \\
\hline Arranging follow-up & $11(4)$ & $15(8)$ & $14(25)$ & $7(4)$ & $12(8)$ & $14(29)$ & $4(5)$ & $3(10)$ & $0(0)$ \\
\hline Waiting for consultant recommendations & $17(7)$ & $13(7)$ & $5(9)$ & $16(9)$ & $12(8)$ & $5(10)$ & $1(1)$ & $1(3)$ & $0(0)$ \\
\hline Other & $1(<1)$ & $12(7)$ & $2(4)$ & $1(1)$ & $12(8)$ & $2(4)$ & $0(0)$ & $0(0)$ & $0(0)$ \\
\hline
\end{tabular}

Top three groups bolded for ease of comparison. Service type is missing from 3 evaluations for 3 patients by 1 provider.

apatients could be identified as being definite discharges at multiple time points. More than one barrier could be identified per patient at any given survey time.

bPM timeframe represents only data from previously identified patient encounters at time points 1 and 2 .

longest, or other) and then to identify all patients they thought would be definite discharges sometime during the day of the survey. Definite discharges were defined as patients whom the provider thought were either currently ready for discharge or who had only minor barriers that, if unresolved, would not prevent same-day discharge. They were asked if the discharge order had been entered and, if not, what was preventing them from doing so, if the discharge could in their opinion have occurred the day prior and, if so, why this did not occur. We also obtained the date and time of the admission and discharge orders, the actual discharge time, as well as the length of stay either through chart review (majority of sites) or from data warehouses (Denver Health and Presbyterian St. Lukes had length of stay data retrieved from their data warehouse).

Physicians were also asked to identify all patients whom they thought might possibly be discharged that day. Possible discharges were defined as patients with barriers to discharge that, if unresolved, would prevent same-day discharge. For each of these, the physicians were asked to list whatever issues needed to be resolved prior to placing the discharge order (Appendix 1).

The second survey was administered late morning on the same day, typically between $11 \mathrm{AM}$ and $12 \mathrm{PM}$. In this survey, the physicians were asked to reassess the patients previously classified as definite and possible discharges for changes in status and/or barriers and to identify patients who had become definite or possible discharges since the earlier survey. Newly identified possible or definite discharges were evaluated in a similar manner as the initial survey.

The third survey was administered midafternoon, typically around 3 PM similar to the first two surveys, with the exception that the third survey did not attempt to identify new definite or possible discharges.

\section{Sample Size}

We stopped collecting data after obtaining a convenience sample of $5 \%$ of total discharges at each study site or on the study end date, which was May 31, 2016, whichever came first.

\section{Data Analysis}

Data were collected and managed using a secure, web-based application electronic data capture tool (REDCap), hosted at Denver Health. REDCap (Research Electronic Data Capture, Nashville, Tennessee) is designed to support data collection for research studies. ${ }^{27}$ Data were then analyzed using SAS Enterprise Guide 5.1 (SAS Institute, Inc., Cary, North Carolina). All data entered into REDCap were reviewed by the principal investigator to ensure that data were not missing, and when there were missing data, a query was sent to verify if the data were retrievable. If retrievable, then the data would be entered. The volume of missing data that remained is described in our results. 
TABLE 3. Physician-Perceived Barriers to Discharge among Patients Identified as Possible Discharges by Teaching Team or Nonteaching Team ${ }^{a}$

\begin{tabular}{|c|c|c|c|c|c|c|c|c|c|}
\hline & \multicolumn{3}{|c|}{ All Service Types } & \multicolumn{3}{|c|}{ Teaching } & \multicolumn{3}{|c|}{ Nonteaching } \\
\hline & $\begin{array}{c}\text { AM } \\
(N=1,181)\end{array}$ & $\begin{array}{c}\text { Noon } \\
(N=693)\end{array}$ & $\begin{array}{c}P^{b} \\
(N=194)\end{array}$ & $\begin{array}{c}\text { AM } \\
N=891\end{array}$ & $\begin{array}{l}\text { Noon } \\
N=537\end{array}$ & $\begin{array}{c}P_{M}^{b} \\
N=161\end{array}$ & $\begin{array}{c}\text { AM } \\
N=287\end{array}$ & $\begin{array}{l}\text { Noon } \\
N=156\end{array}$ & $\begin{array}{c}\mathrm{PM}^{\mathrm{b}} \\
\mathrm{N}=33\end{array}$ \\
\hline Newly identified as possible discharge, $\mathrm{N}(\%)$ & $1,181(100)$ & $55(8)$ & $2(1)$ & $891(100)$ & $45(8)$ & $2(1)$ & $287(100)$ & $10(6)$ & $0(0)$ \\
\hline $\begin{array}{l}\text { Patients identified as possible discharges } \\
\text { with barriers identified }\end{array}$ & $1,181(100)$ & $682(98)$ & $188(97)$ & $891(100)$ & $527(98)$ & $155(96)$ & $287(100)$ & $155(99)$ & $33(100)$ \\
\hline Social work & $280(24)$ & $188(28)$ & $48(26)$ & $243(27)$ & $169(32)$ & $47(30)$ & $37(13)$ & $19(12)$ & $1(3)$ \\
\hline Consultant recommendations & $217(18)$ & $137(20)$ & $45(24)$ & $164(18)$ & $108(20)$ & $36(23)$ & $53(18)$ & $29(19)$ & $9(27)$ \\
\hline Procedure & $147(12)$ & $107(16)$ & $44(23)$ & $100(11)$ & $71(13)$ & $29(19)$ & $47(16)$ & $36(23)$ & $15(45)$ \\
\hline Labs/Radiology & $118(10)$ & $74(11)$ & $21(11)$ & $92(10)$ & $59(11)$ & $17(11)$ & $26(9)$ & $15(10)$ & $4(12)$ \\
\hline PT/OT & $95(8)$ & $69(10)$ & $12(6)$ & $62(7)$ & $50(9)$ & $10(6)$ & $33(12)$ & $19(12)$ & $2(6)$ \\
\hline Missing & 0 & $11(2)$ & $6(3)$ & 0 & $10(2)$ & $6(4)$ & 0 & $1(1)$ & 0 \\
\hline
\end{tabular}

Top three groups bolded for ease of comparison. Service type is missing from three evaluations for three patients by one provider.

aPatients could be identified as being a possible discharge at multiple time points. More than one barrier could be identified per patient at any given survey time.

bPM timeframe represents data from previously identified patient encounters at time points 1 and 2 .

Continuous variables were described using means and standard deviations (SD) or medians and interquartile ranges (IQR) based on tests of normality. Differences in the time that the discharge orders were placed in the electronic medical record according to morning patient census, teaching versus nonteaching service, and rounding style were compared using the Wilcoxon rank sum test. Linear regression was used to evaluate the effect of patient census on discharge order time. $P<.05$ was considered as significant.

\section{RESULTS}

We conducted 1,584 patient evaluations through surveys of 254 physicians over 156 days. Given surveys coincided with the existing work we had full participation (ie, 100\% participation) and no dropout during the study days. Median (IQR) survey time points were 8:30 AM (7:51 AM, 9:12 AM), 11:45 AM (11:30 AM, 12:17 PM), and 3:20 PM (3:00 PM, 4:06 PM).

The characteristics of the five hospitals participating in the study, the patients' final discharge status, the types of physicians surveyed, the services on which they were working, the rounding styles employed, and the median starting daily census are summarized in Table 1. The majority of the physicians surveyed were housestaff working on teaching services, and only a small minority structured rounds such that patients ready for discharge were seen first.

Over the course of the three surveys, 949 patients were identified as being definite discharges at any time point, and the large majority of these $(863,91 \%)$ were discharged on the day of the survey. The median (IQR) time that the discharge orders were written was 11:50 AM (10:35 AM, 1:45 PM).
During the initial morning survey, 314 patients were identified as being definite discharges for that day (representing approximately $6 \%$ of the total number of patients being cared for, or $33 \%$ of the patients identified as definite discharges throughout the day). Of these, the physicians thought that 44 $(<1 \%$ of the total number of patients being cared for on the services) could have been discharged on the previous day. The most frequent reasons cited for why these patients were not discharged on the previous day were "Patient did not want to leave" $(n=15,34 \%)$, "Too late in the day" $(n=10,23 \%)$, and "No ride" ( $n=9,20 \%)$. The remaining 10 patients (23\%) had a variety of reasons related to system or social issues (ie, shelter not available, miscommunication).

At the morning time point, the most common barriers to discharge identified were that the physicians had not finished rounding on their team of patients and that the housestaff needed to staff their patients with their attending. At noon, caring for other patients and tending to the discharge processes were most commonly cited, and in the afternoon, the most common barriers were that the physicians were in the process of completing the discharge paperwork for those patients or were discharging other patients (Table 2). When comparing barriers on teaching to nonteaching teams, a higher proportion of teaching teams were still rounding on all patients and were working on discharge paperwork at the second survey. Barriers cited by sites were similar; however, the frequency at which the barriers were mentioned varied (data not shown).

The physicians identified 1,237 patients at any time point as being possible discharges during the day of the survey and these had a mean $( \pm S D)$ of $1.3( \pm 0.5)$ barriers cited for why 
TABLE 4. Effect of Starting Census, Rounding Style, and Teaching versus Nonteaching Service on Discharge Order Time and Discharge Time

\begin{tabular}{|c|c|c|c|c|c|c|}
\hline & $\begin{array}{l}\text { Patients with Discharge } \\
\text { Orders Placed } \\
(\mathrm{N}=863)\end{array}$ & $\begin{array}{l}\text { Median Discharge } \\
\text { Order Time, } \\
\text { Hour (IQR) }\end{array}$ & $P$ Value & $\begin{array}{l}\text { Patients Discharged } \\
\text { from Hospital } \\
\qquad(\mathrm{N}=822)^{\mathrm{a}}\end{array}$ & $\begin{array}{c}\text { Median Discharge } \\
\text { Time, Hour (IQR) }\end{array}$ & $P$ Value \\
\hline Starting census, N (\%) & & & .0003 & & & .0057 \\
\hline 0-11 patients & $498(58)$ & $\begin{array}{c}11: 31 \\
(10: 20,13: 31)\end{array}$ & & $459(56)$ & $\begin{array}{c}14: 47 \\
(12: 45 ; 16: 37)\end{array}$ & \\
\hline 12 and greater & $365(42)$ & $\begin{array}{c}12: 14 \\
(10: 57,14: 01)\end{array}$ & & $363(44)$ & $\begin{array}{c}15: 14 \\
(13: 15,17: 03)\end{array}$ & \\
\hline Rounding style, N (\%) & & & .0026 & & & .0010 \\
\hline Discharges first & $82(10$ & $\begin{array}{c}11: 07 \\
(9: 40,13: 15)\end{array}$ & & $80(10)$ & $\begin{array}{c}14: 00 \\
(12: 11,15: 32)\end{array}$ & \\
\hline All other styles & $671(78)$ & $\begin{array}{c}11: 55 \\
(10: 37,13: 48)\end{array}$ & & $632(77)$ & $\begin{array}{c}15: 00 \\
(13: 07,16: 57)\end{array}$ & \\
\hline Missing ${ }^{b}$ & $110(13)$ & $\begin{array}{c}12: 03 \\
(11: 01,13: 47)\end{array}$ & & $110(13)$ & $\begin{array}{c}15: 05 \\
(13: 30,16: 51)\end{array}$ & \\
\hline Teaching, N (\%) & & & $<.0001$ & & & $<.0001$ \\
\hline Yes & $608(71)$ & $\begin{array}{c}12: 04 \\
(11: 00,14: 00)\end{array}$ & & $567(69)$ & $\begin{array}{c}15: 06 \\
(13: 20,17: 03)\end{array}$ & \\
\hline No & $252(29)$ & $\begin{array}{c}11: 06 \\
(9: 32,13: 03)\end{array}$ & & $252(31)$ & $\begin{array}{c}14: 29 \\
(12: 27,16: 05)\end{array}$ & \\
\hline Missing & $3(<1)$ & $\begin{array}{c}11: 22 \\
(11: 04,13: 23)\end{array}$ & & $3(<1)$ & $\begin{array}{c}17: 30 \\
(16: 20,18: 00)\end{array}$ & \\
\hline
\end{tabular}

${ }^{a} 41(5 \%)$ of 863 patients with a discharge order placed were missing the date/time stamp for discharge.

${ }^{\mathrm{b}}$ Missing data at the patient level.

these patients were possible rather than definite discharges. The most common were that clinical improvement was needed, one or more pending issues related to their care needed to be resolved, and/or awaiting pending test results. The need to see clinical improvement generally decreased throughout the day as did the need to staff patients with an attending physician, but barriers related to consultant recommendations or completing procedures increased (Table 3). Of the 1,237 patients ever identified as possible discharges, 594 (48\%) became a definite discharge by the third call and 444 (36\%) became a no discharge as their final status. As with definite discharges, barriers cited by sites were similar; however, the frequency at which the barriers were mentioned varied.

Among the 949 and 1,237 patients who were ever identified as definite or possible discharges, respectively, at any time point during the study day, 28 (3\%) and 444 (36\%), respective$l y$, had their discharge status changed to no discharge, most commonly because their clinical condition either worsened or expected improvements did not occur or that barriers pertaining to social work, physical therapy, or occupational therapy were not resolved.

The median time that the discharge orders were entered into the electronic medical record was 43 minutes earlier if patients were on teams with a lower versus a higher starting census $(P=$ .0003), 48 minutes earlier if they were seen by physicians whose rounding style was to see patients first who potentially could be discharged $(P=.0026)$, and 58 minutes earlier if they were on nonteaching versus teaching services $(P<.0001$; Table 4).
For every one-person increase in census, the discharge order time increased by 6 minutes $(\beta=5.6, \mathrm{SE}=1.6, P=.0003)$.

\section{DISCUSSION}

The important findings of this study are that (1) the large majority of issues thought to delay discharging patients identified as definite discharges were related to physicians caring for other patients on their team, (2) although $91 \%$ of patients ever identified as being definite discharges were discharged on the day of the survey, only $48 \%$ of those identified as possible discharges became definite discharges by the afternoon time point, largely because the anticipated clinical improvement did not occur or care being provided by ancillary services had not been completed, and (3) discharge orders on patients identified as definite discharges were written on average 50 minutes earlier by physicians on teams with a smaller starting patient census, on nonteaching services, or when the rounding style was to see patients ready for discharges first.

Previous research has reported that physician-perceived barriers to discharge were extrinsic to providers and even extrinsic to the hospital setting (eg, awaiting subacute nursing placement and transportation). ${ }^{28,29}$ However, many of the barriers that we identified were related directly to the providers' workload and rounding styles and whether the patients were on teaching versus nonteaching services. We also found that delays in the ability of hospital services to complete care also contributed to delayed discharges.

Our observational data suggest that delays resulting from car- 
ing for other patients might be reduced by changing rounding styles such that patients ready for discharge are seen first and are discharged prior to seeing other patients on the team, as previously reported by Beck et al..$^{30}$ Intuitively, this would seem to be a straightforward way of freeing up beds earlier in the day, but such a change will, of necessity, lead to delaying care for other patients, which, in turn, could increase their length of stays. Durvasula et al. suggested that discharges could be moved to earlier in the day by completing orders and paperwork the day prior to discharge..$^{25}$ Such an approach might be effective on an Obstetrical or elective Orthopedic service on which patients predictably are hospitalized for a fixed number of days (or even hours) but may be less relevant to patients on internal medicine services where lengths of stay are less predictable. Interventions to improve discharge times have resulted in earlier discharge times in some studies, ${ }^{2,4}$ but the overall length of stay either did not decrease ${ }^{25}$ or increased ${ }^{31}$ in others. Werthheimer et al. did find earlier discharge times, but other interventions also occurred during the study period (eg, extending social work services to include weekends). ${ }^{1,32}$

We found that discharge times were approximately $50 \mathrm{~min}$ utes earlier on teams with a smaller starting census, on nonteaching compared with teaching services, or when the attending's rounding style was to see patients ready for discharges first. Although 50 minutes may seem like a small change in discharge time, Khanna et al. ${ }^{33}$ found that when discharges occur even 1 hour earlier, hospital overcrowding is reduced. To have a lower team census would require having more teams and more providers to staff these teams, raising cost-effectiveness concerns. Moving to more nonteaching services could represent a conflict with respect to one of the missions of teaching hospitals and raises a cost-benefit issue as several teaching hospitals receive substantial funding in support of their teaching activities and housestaff would have to be replaced with more expensive providers.

Delays attributable to ancillary services indicate imbalances between demand and availability of these services. Inappropriate demand and inefficiencies could be reduced by systems redesign, but in at least some instances, additional resources will be needed to add staff, increase space, or add additional equipment.

Our study has several limitations. First, we surveyed only physicians working in university-affiliated hospitals, and three of these were public safety-net hospitals. Accordingly, our results may not be generalizable to different patient populations. Second, we surveyed only physicians, and Minichiello et al. ${ }^{29}$ found that barriers to discharge perceived by physicians were different from those of other staff. Third, our data were observational and were collected only on weekdays. Fourth, we did not differentiate interns from residents, and thus, potentially the level of training could have affected these results. Similarly, the decision for a "possible" and a "definite" discharge is likely dependent on the knowledge base of the participant, such that less experienced participants may have had differing perspectives than someone with more experience. Fifth, the sites did vary based on the infrastructure and support but also had several similarities. All sites had social work and case management involved in care, although at some sites, they were assigned according to team and at others according to geographic location. Similarly, rounding times varied. Most of the services surveyed did not utilize advanced practice providers (the exception was the nonteaching services at Denver Health, and their presence was variable). These differences in staffing models could also have affected these results.

Our study also has a number of strengths. First, we assessed the barriers at five different hospitals. Second, we collected real-time data related to specific barriers at multiple time points throughout the day, allowing us to assess the dynamic nature of identifying patients as being ready or nearly ready for discharge. Third, we assessed the perceptions of barriers to discharge from physicians working on teaching as well as nonteaching services and from physicians utilizing a variety of rounding styles. Fourth, we had a very high participation rate (100\%), probably due to the fact that our study was strategically aligned with participants' daily work activities.

In conclusion, we found two distinct categories of issues that physicians perceived as most commonly delaying writing discharge orders on their patients. The first pertained to patients thought to definitely be ready for discharge and was related to the physicians having to care for other patients on their team. The second pertained to patients identified as possibly ready for discharge and was related to the need for care to be completed by a variety of ancillary services. Addressing each of these barriers would require different interventions and a need to weigh the potential improvements that could be achieved against the increased costs and/or delays in care for other patients that may result.

Disclosures: The authors report no conflicts of interest relevant to this work.

\section{References}

1. Wertheimer B, Jacobs RE, Bailey M, et al. Discharge before noon: an achievable hospital goal. J Hosp Med. 2014;9(4):210-214. doi: 10.1002/jhm.2154

2. Kane $M$, Weinacker $A$, Arthofer $R$, et al. A multidisciplinary initiative to increase inpatient discharges before noon. J Nurs Adm. 2016;46(12):630-635. doi: 10.1097/NNA.0000000000000418.

3. Khanna S, Sier D, Boyle J, Zeitz K. Discharge timeliness and its impact on hospital crowding and emergency department flow performance. Emerg Med Australas. 2016;28(2):164-170. doi: 10.1111/1742-6723.12543.

4. Kravet SJ, Levine RB, Rubin HR, Wright SM. Discharging patients earlier in the day: a concept worth evaluating. Health Care Manag (Frederick). 2007;26:142-146. doi: 10.1097/01.HCM.0000268617.33491.60.

5. Khanna S, Boyle J, Good N, Lind J. Impact of admission and discharge peak times on hospital overcrowding. Stud Health Technol Inform. 2011;168:82-88. doi: 10.3233/978-1-60750-791-8-82.

6. McGowan JE, Truwit JD, Cipriano P, et al. Operating room efficiency and hospital capacity: factors affecting operating room use during maximum hospital census. J Am Coll Surg. 2007;204(5):865-871; discussion 71-72. doi: 10.1016/j.jamcollsurg.2007.01.052

7. Khanna S, Boyle J, Good N, Lind J. Early discharge and its effect on ED length of stay and access block. Stud Health Technol Inform. 2012;178:92-98. doi: 10.3233/978-1-61499-078-9-92

8. Powell ES, Khare RK, Venkatesh AK, Van Roo BD, Adams JG, Reinhardt $\mathrm{G}$. The relationship between inpatient discharge timing and emergency department boarding. J Emerg Med. 2012;42(2):186-196. doi: 10.1016/j. jemermed.2010.06.028.

9. Wertheimer B, Jacobs RE, Iturrate E, Bailey M, Hochman K. Discharge before 
noon: Effect on throughput and sustainability. J Hosp Med. 2015;10(10):664 669. doi: 10.1002/jhm.2412

10. Sikka R, Mehta S, Kaucky C, Kulstad EB. ED crowding is associated with an increased time to pneumonia treatment. Am J Emerg Med. 2010;28(7):809812. doi: 10.1016/j.ajem.2009.06.023.

11. Coil CJ, Flood JD, Belyeu BM, Young P, Kaji AH, Lewis RJ. The effect of emergency department boarding on order completion. Ann Emerg Med. 2016;67:730-736 e2. doi: 10.1016/j.annemergmed.2015.09.018.

12. Gaieski DF, Agarwal AK, Mikkelsen ME, et al. The impact of ED crowding on early interventions and mortality in patients with severe sepsis. Am J Emerg Med. 2017;35:953-960. doi: 10.1016/j.ajem.2017.01.061.

13. Pines JM, Localio AR, Hollander JE, et al. The impact of emergency department crowding measures on time to antibiotics for patients with community-acquired pneumonia. Ann Emerg Med. 2007;50(5):510-516. doi: 10.1016/j. annemergmed.2007.07.021.

14. Hwang U, Richardson L, Livote E, Harris B, Spencer N, Sean Morrison R. Emergency department crowding and decreased quality of pain care. Acad Emerg Med. 2008;15:1248-1255. doi: 10.1111/j.1553-2712.2008.00267.x.

15. Mills AM, Shofer FS, Chen EH, Hollander JE, Pines JM. The association between emergency department crowding and analgesia administration in acute abdominal pain patients. Acad Emerg Med. 2009;16:603-608. doi 10.1111/j.1553-2712.2009.00441.x.

16. Pines JM, Shofer FS, Isserman JA, Abbuhl SB, Mills AM. The effect of emergency department crowding on analgesia in patients with back pain in two hospitals. Acad Emerg Med. 2010;17(3):276-283. doi: 10.1111/j.15532712.2009.00676.x

17. Kulstad EB, Sikka R, Sweis RT, Kelley KM, Rzechula KH. ED overcrowding is associated with an increased frequency of medication errors. Am J Emerg Med. 2010;28:304-309. doi: 10.1016/j.ajem.2008.12.014

18. Richardson DB. Increase in patient mortality at 10 days associated with emergency department overcrowding. Med J Aust. 2006;184(5):213-216.

19. Hoot NR, Aronsky D. Systematic review of emergency department crowding: causes, effects, and solutions. Ann Emerg Med. 2008;52(2):126-136. doi: 10.1016/j.annemergmed.2008.03.014.

20. Singer AJ, Thode HC, Jr., Viccellio P, Pines JM. The association between length of emergency department boarding and mortality. Acad Emerg Med. 2011;18(12):1324-1329. doi: 10.1111/j.1553-2712.2011.01236.x.

21. White BA, Biddinger PD, Chang Y, Grabowski B, Carignan S, Brown DF. Boarding inpatients in the emergency department increases discharged patient length of stay. J Emerg Med. 2013;44(1):230-235. doi: 10.1016/j. jemermed.2012.05.007.

22. Forster AJ, Stiell I, Wells G, Lee AJ, van Walraven C. The effect of hospital occupancy on emergency department length of stay and patient disposition. Acad Emerg Med. 2003;10(2):127-133. doi: 10.1197/aemj.10.2.127.

23. Foley M, Kifaieh N, Mallon WK. Financial impact of emergency department crowding. West J Emerg Med. 2011;12(2):192-197.

24. Pines JM, lyer S, Disbot M, Hollander JE, Shofer FS, Datner EM. The effect of emergency department crowding on patient satisfaction for admitted patients. Acad Emerg Med. 2008;15(9):825-831. doi: 10.1111/j.15532712.2008.00200.x

25. Durvasula R, Kayihan A, Del Bene S, et al. A multidisciplinary care pathway significantly increases the number of early morning discharges in a large academic medical center. Qual Manag Health Care. 2015;24:45-51. doi: 10.1097/ QMH.0000000000000049.

26. Cho HJ, Desai N, Florendo A, et al. E-DIP: Early Discharge Project. A Model for Throughput and Early Discharge for 1-Day Admissions. BMJ Qual Improv Rep. 2016;5(1): pii: u210035.w4128. doi: 10.1136/bmjquality.u210035.w4128.

27. Harris PA, Taylor R, Thielke R, Payne J, Gonzalez N, Conde JG. Research electronic data capture (REDCap)--a metadata-driven methodology and workflow process for providing translational research informatics support. $J$ Biomed Inform. 2009;42(2):377-381. doi: 10.1016/j.jbi.2008.08.010.

28. Patel H, Fang MC, Mourad M, et al. Hospitalist and internal medicine leaders' perspectives of early discharge challenges at academic medical centers. J Hosp Med. 2018;13(6):388-391. doi: 10.12788/jhm.2885

29. Minichiello TM, Auerbach AD, Wachter RM. Caregiver perceptions of the reasons for delayed hospital discharge. Eff Clin Pract. 2001;4(6):250-255

30. Beck MJ, Okerblom D, Kumar A, Bandyopadhyay S, Scalzi LV. Lean intervention improves patient discharge times, improves emergency department throughput and reduces congestion. Hosp Pract (1995). 2016;44(5):252-259. doi: 10.1080/21548331.2016.1254559.

31. Rajkomar A, Valencia V, Novelero M, Mourad M, Auerbach A. The association between discharge before noon and length of stay in medical and surgical patients. J Hosp Med. 2016;11(12):859-861. doi: 10.1002/jhm.2529.

32. Shine D. Discharge before noon: an urban legend. Am J Med. 2015;128(5):445446. doi: 10.1016/j.amjmed.2014.12.011.

33. Khanna S, Boyle J, Good N, Lind J. Unravelling relationships: Hospital occupancy levels, discharge timing and emergency department access block. Emerg Med Australas. 2012;24(5):510-517. doi: 10.1111/j.1742-6723.2012.01587.x. 